\title{
Erratum to: Multi-objective optimization for draft scheduling of hot strip mill
}

\author{
LI Wei-gang(李维刚) $)^{1,2}$, LIU Xiang-hua(刘相华) ${ }^{3}$, GUO Zhao-hui(郭朝晖) $)^{1,2}$
}

1. College of Information Science and Engineering, Northeastern University, Shenyang 110819, China;

2. Automation Division of Research Institute, Baosteel Group Corporation, Shanghai 201900, China;

3. Research Institute of Science and Technology, Northeastern University, Shenyang 110819, China

(C) Central South University Press and Springer-Verlag Berlin Heidelberg 2012

Erratum to: J. Cent. South Univ. (2012) 19: 3069-3078

DOI: $10.1007 / \mathrm{s} 11771-012-1380-\mathrm{z}$

The original version of this article unfortunately contained mistakes.

1) The first two sentences of Abstract were missing. The corrected sentences are given below.

A multi-objective optimization model for draft scheduling of hot strip mill was presented, which considers rolling power minimizing, rolling force ratio distribution and good strip shape as the objective functions. A multi-objective differential evolution algorithm based on decomposition (MODE/D) was used to solve this model.

2) An incorrect word existed in the first sentence of Section 4.1. The corrected sentence is given below.

Obtain the related strip set-up items of the process control computer and equipment capacity of the hot strip mill, then perform the multi-objective optimization for draft scheduling by MODE/D to get Pareto-optimal solutions.

3) The title of the 9th column of Table 6 was incorrect. The corrected title is $f_{2} / 10^{6}$.

The online version of the original article can be found at http://dx.doi.org/10.1007/s11771-012-1380-z 